\title{
An Analysis of Determinants of Office Rental Values in Sri Jayewardenepura
}

Dissertation submitted to the Universitity off Shii Vayewardlemepura as a partiial fulfillment for the requinzememts of the final examination of the M.Sc. in Real Estate Managememt and Valuation Degree.

Full Namie

Examination No

Registration No

Department

University

Date of Submission
: P S Ranaweera

: REMV / 82

: GS / M.Sc / REMV / 3770/ 09

: Estate Managememt and Valuation

: Universitty off Shii Janyeowandemeptura

: 03.12. 2012

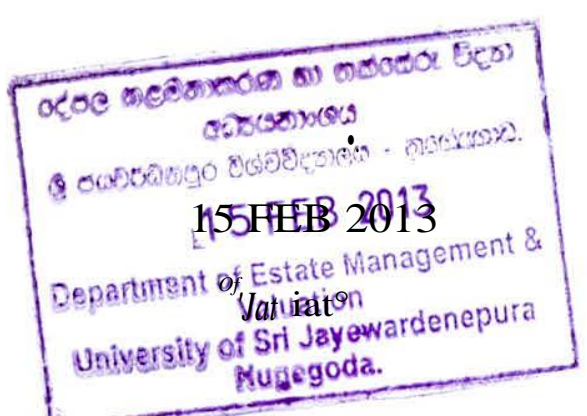


The work described in this dissertation was carried out under the supervision of Mrs. N.C. Wickramaarachchi, Senior Lecturer of the Department of Estate Management and Valuation and any report on this has not been submitted in whole or in part to any university or any other institute for another degree / examination or any other purpose.

Full Name

Examination No

Signature of the Candidate

Date
: P S Ranaweera

: REMV / 82

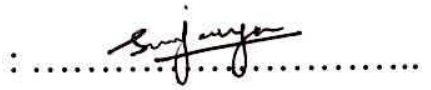

: 03.12 .2012 
Hereby, I certify that Mr. Pani Sanjaya Ranaweera, (GS / M.Sc / REMV / 3770 / 09) duly completed the research titled "An Analysis of determinants of office rental values in Sri Jayewardenepura" under my supervision and recommended to submit for the final submission.
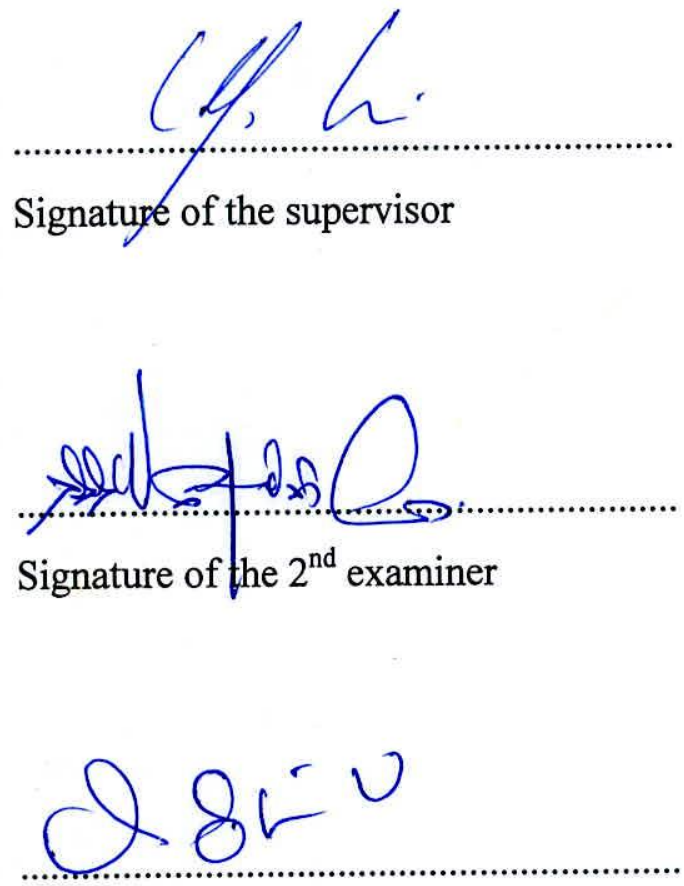

Signature and the official stamp of the Head

\section{Head}

Department of Estate Management \& Valuation

University of Sri Jsyewardenepura

Nugegoda, Sri ianka. 


\section{Acknowledgements}

First I sincerely thank to my employer, the Urban Development Authority (UDA) and specially Mr. Prasanna Silva, former Director General and Mr.G.W.G. Abeygunawardena, Director (LD \& Mgt.) of the UDA who have made arrangements for me to undertake the M.Sc. in Real Estate Management and Valuation Degree course.

I wish to express my deep sense of gratitude to my Supervisor, Mrs. N.C. Wickramaarachchi, Senior Lecturer of Department of Real Estate Management \& Valuation for her constant supervision and advice in completing the research study. Her exemplary guidance, monitoring and ideas in numerous discussions throughout the research process contributed immensely to the success of my dissertation. I am truly indebted for her commitment and support.

I would like to thank the Head of the Department of Estate Management \& Valuation, University of Sri Jayewardenepura and being the Course Coordinator Mrs. K G P K Weerakoon for her valuable comments and support to undertake the research.

I recorded my sincere gratitude and appreciate to Mr. A. A. M. Fathihu, Govt. Chief Valuer, Mrs. S R Amarasinghe, Regional Valuer (Western Central Region), and Mr. G D Seneviratne, Regional Valuer (Colombo Metro Region) also my colleagues and friends at the Govt. Valuation Department who kindly support me to collect most of data employed.

My colleagues and all other personal that have helped me in many ways in accomplishing my research study, I must express my sincere gratitude to them.

Last but not the least, words of deep gratitude goes to my parents and brother for their love, their help, for always trusting and supporting me. 


\begin{abstract}
The contribution of the service sector for the GDP of the country is dominant being accounts for $59.5 \%$ of GDP. Office properties where most of the service sector activities are taken place reflect it as one of important aspects of the economy of the country. An office property is one of main category of commercial properties and also heterogeneous goods. Hence, office property is associated with a bundle of characteristics related to physical, range of quality attributes and specific locational characteristics as residential properties. Property valuation is dealt with identification, analysis and quantification of these various kinds of attributes in order to determine the value of a particular property. Literature established that the Hedonic Regression Analysis is the most common method used in the previous studies which analyse the rent determinants and formulate rent models initially for residential properties, in the past two decades this technique has also been applied in a host of office market analysis to predict rent. Hence, it is encouraged to study on office market of the country and this research attempts to examine significant determinants of office rent through the Hedonic regression Analysis. The primary objective of this study is to identify significant office rent determinants with special reference to Sri Jayewardenepura Kotte being the Administrative Capital of the country and focus on spatial variation of rent determinants by selecting two specific town centers situated in the study area.
\end{abstract}

The study uses data, obtained from rating cards maintain by the Govt. Valuation Department for office properties and through a field survey. The stated rental values which are more or less similar to the actual rental values mentioned in rating cards, have been applied as dependant variables along with 16 independent variables as predictors to run multiple regression analysis. The OLS estimation has been applied using SPSS for the analysis. In addition, determinants of rating rent other than stated rent also has been examined based on the rating rent data available for all office units which have been selected from the two specific locations namely Nugegoda and Battaramulla.

The results generated from the analysis indicated that the floor area or size, type of building, vertical location related to physical attributes, availability of car parking, air condition facilities as building amenities and location of office units, were among the significant predictors of office rent. Out of which it was found that size or floor area of office unit was the most influencing predictor of rent, where $1 \%$ increase of which accounts for about $74 \%$ and $73 \%$ positive effect of monthly stated rent in Nugegoda and Battaramulla areas respectively. As far as its impact on rating rent is concerned, it accounts for about $84 \%$ and $93 \%$ of rating rent in respective areas, reflecting its influence on rating rent variation which is stronger than stated rent. Other than these predictors condition of office unit, the availability of reception area and zone were also found as significant determinants on rating rent of office properties in two areas. Importantly, the explanatory powers of rent models are concerned, stated rent models were explained about $84 \%$ and $74 \%$ rent variations in Nugegoda and Battaramulla areas respectively. It was further revealed that office rent determinants and their influences on rental values spatially vary depending on different geographical areas. 


\section{Table of Contents}

Acknowledgement...................................i

Abstract..............................................ii

Table of Contents....................................iii

List of Tables..........................................vi

List of Figures........................................ viii

\section{Contents}

Pages

CHAPTER ONE - Introduction

01-05

1.1. Background of the study 01

1.2. Research Problem 03

1.3. Significance of the Study 04

1.4. Objective of the Study 05

1.4.1. General Objective 05

1.4.2. Specific Objectives 05

CHAPTER TWO - Literature Review $\quad$ 06-48

2.1 Introduction 06

2.2. History of Rent Model 06

2.3. Hedonic Price Model (HP Model) 07

2.4. Studies on Hedonic Price Models of office rents 11

2.5. Office Property or Office Space 39

2.6. Types of Office Rental Data 40

2.6.1. Asking rent 41

2.6.2. Headline rent 41

2.6.3. Consideration rent and Effective rent 42

2.7. Principle determinants of rental value of office property 42

2.7.1. Econometric Determinants 43

2.7.2. Physical Characteristics 43

2.7.3. Locational Characteristics 45

2.7.4. Lease or Contract Characteristics $\quad 47$

2.8. Conclusion 48 
3.1. Introduction $\quad 49$

3.2. Research Design 49

3.3. Theoretical Framework $\quad 50$

3.4. Research Process $\quad 52$

3.4.1. Identification of Variables 52

3.4.2. Empirical Model 56

3.4.3. Selection of Study Area $\quad 57$

3.4.4. Population and Sample 58

3.4.5. Data Collection and Methods $\quad 59$

CHAPTER FOUR - Background of the Study Area 61-73

$\begin{array}{ll}\text { 4.1. Introduction } & 61\end{array}$

4.2. Selection of Study Area $\quad 61$

4.3. Administrative Capital 62

4.3.1. Regional Context 62

4.3.2. Demographic Profile $\quad 64$

4.3.3. Employment Profile 66

4.3.4. Land Use Profile $\quad 67$

4.3.5. Distribution of Building Units $\quad 69$

4.4. Selection of two Urban Centers 70

CHAPTER FIVE - Data Analysis $\quad$ 74-117

5.1. Introduction $\quad 74$

5.2. Comparison of Rental Values 74

$\begin{array}{ll}\text { 5.3. Comparison of Physical Characteristics } & 79\end{array}$

5.4. Comparison of Building Amenities 86

5.5. Comparison of Locational Characteristics 88

5.6. Correlation Statistics 90

5.7. Hypothesis Testing 93

5.7.1. Hypotheses testing for Rating rent in Nugegoda area 95

5.7.2. Hypotheses testing for Stated rent in Nugegoda area 97

5.7.3. Hypotheses testing for Rating rent in Battaramulla area 98 
5.7.4. Hypotheses testing for stated rent in Battaramulla area

5.8. Estimation Results 101

5.8.1. Estimation Results for Model 1

5.8.2. Estimation Results for Model 2

5.8.3. Estimation Results of Model 3 for the variables with the significance 107 level of $10 \%$ or less

5.8.4. Estimation Results of Model 4 for the variables with the significance 109 level of $10 \%$ or less

5.8.5. Estimation Results of Model 5 for the variables with the significance 111 level of $5 \%$ or less

5.8.6. Estimation Results of Model 6 for the variables with the significance level of $5 \%$ or less

5.9. Spatial Variation of Office Rent Determinants

5.9.1. Comparison of Spatial Variation of rating rent determinants

5.9.2. Comparison of Spatial Variation of stated rent determinants 


\section{List of Tables}

\section{Table}

Pages

2.1. Office Rent Types 41

3.1. Variables Description $\quad 55$

3.2 Selected Explanatory Variables Adopted by Researchers 56

3.3. Office units selected for the samples 58

4.1. Population Growth Rate Municipal Area of Sri Jayawardenapura Kotte 64

4.2. Population distribution and density of Colombo district in 2012

4.3. Population on three Administrative units in $1971-2012$

4.4. Employed population aged 10 years and over in 2001

4.5. Change in the Land Use Pattern in 1985 \& 2003

4.6. Land Use Pattern in 2004 Kaduwela Pradeshiya Sabha Area 69

4.7. Building Units - $2011 \quad 70$

4.8. Population, Employment and building units of town areas 70

5.1. Monthly rating rents of two areas 75

5.2. Rating rents per(sq.ft.) of two areas 76

5.3. Monthly stated rents of two areas. 77

5.4. Monthly stated rents (Sq.ft.) of two areas 77

5.5. Floor area of office units in two areas 80

5.6. Age of Office units in two areas 81

5.7. Number of floors of Office units in two areas 82

5.8. Vertical Location of Office units in two areas 83

5.9. Type of office building in two areas 85

5.10. Exterior Walls finishes of office units in two areas 85

5.11. Floor finishes of office units in two areas 85

5.12. Condition of office units in two areas 86

5.13. Parking Facilities of office units in two areas 86

5.14. Air condition Facilities of office units in two areas 87

5.15. Reception area of office units in two areas 87

5.16. Attached bath and toilet of office units in two areas 87

5.17. Lift facilities of office units in two areas 88

5.18. Distance to Town Center from office units in two areas 88 
5.19. Locality of office units in two areas $\quad 89$

5.20. Zone of office units in two areas $\quad 89$

5.21. Correlations of variables represent attributes of office units in Nugegoda area

5.22. Correlations of variables represent attributes of office units in

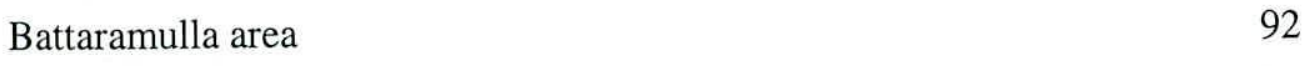

5.23. Variables with expected signs 94

5.24. Results of hypothesis testing for rating rent in Nugegoda area 96

5.25. Modal summary for rating rent in Nugegoda area 96

5.26. Results of hypothesis testing for stated rent in Nugegoda 97

5.27. Modal summary for stated rent in Nugegoda 98

5.28. Results of hypotheses testing for rating rent in Battaramulla 99

5.29. Modal summary for rating rent in Battaramulla 99

5.30. Results of hypotheses testing for stated rent in Battaramulla 100

5.31. Modal summary for stated rent in Battaramulla 101

5.32. Model 1 result for Nugegoda 102

5.33. Model 1 result for Battaramulla 103

5.34. Model 2 result for Nugegoda 105

5.35. Model 2 result for Battaramulla 106

5.36. Model 3 result for Nugegoda 108

5.37. Model 3 result for Battaramulla 108

5.38. Model 4 result for Nugegoda 109

5.39. Model 4 result for Battaramulla 110

5.40. Model 5 result for Nugegoda 111

5.41. Model 5 result for Battaramulla $\quad 112$

5.42. Model 6 result for Battaramulla 113

5.43. Spatial Variation of rating rent determinants in two areas 115

5.44. Spatial Variation of stated rent determinants in two areas 116 


\section{List of Figures}

Figure

Pages

3.1. Conceptual Framework 51

3.2. Models used for analysis $\quad 60$

4.1. Location Map of Study Area 63

4.2. Population of Study Area 66

4.3. Location of office buildings at Nugegoda selected for the sample 72

4.4. Location of office buildings at Battaramulla selected for the sample 73

5.1. Rating rent in Battaramulla 75

5.2- Rating rent (sq.ft) in Battaramulla 75

5.3 Rating rent in Nugegoda $\quad 76$

5.4. Rating rent (sq.ft) in Nugegoda 76

5.5. Stated rent in Battaramulla 78

5.6. Stated rent (sq.ft) in Battaramulla 78

5.7. Stated rent in Nugegoda 79

$\begin{array}{ll}\text { 5.8. Stated rent (sq.ft) in Nugegoda } & 79\end{array}$

5.9. Floor area of office units in Battaramulla $\quad 80$

5.10. Floor area of office units in Nugegoda $\quad 80$

5.11. Age of office units in Battaramulla 82

5.12 Age of office units in Nugegoda $\quad 82$

5.13. No. of floors of office units in Battaramulla 83

5.14. No. of floors of office units in Nugegoda 83

5.15. Vertical Location of office units in Battaramulla 84

5.16. Vertical Location of office units in Nugegoda 84

5.15. Distance to Town from office units in Battaramulla 89

5.16. Distance to Town from offices in Nugegoda 89

\section{Annexure}

Data collection Form 


\section{CHAPTER 01}

\section{Introduction}

\subsection{Background of the Study}

Determinants of rental values of different type of real estate properties have been examined by previous empirical studies which mainly focused to identify and quantify determinants of rent in relation to residential properties. These studies have identified market rent determinants under three broad categories namely, property specific attributes, management specific factors and vacancies and findings indicated that location, quality attributes and amenities are the significant determinants of rent.

Most of the previous studies analyzed determinants of rental values in the property markets used Hedonic Price Model which is the typical statistical technique applied by many researchers as it has proved its reliability of establishing implicit price of individual attributes of property and their marginal contribution to overall property value.

As residential property an office is also heterogeneous goods which is associated with a bundle of characteristics such as size, age, range of quality attributes and lease terms. Being physical asset, it has its own specific location. These unique set of characteristics affect its value. Property valuation is dealt with the identification, analysis and quantification of these characteristics. Hence, a different bundle of characteristics inherent in each office property make valuation difficult.

Eda (2003) discussed the importance of commercial property related to three different factors: First as a factor of production, it provides the space to house the activities of business and industry. Second, as financial asset, commercial property constitutes a significant part within asset market. Third, as an investment medium, it provides revenue to its holders on the basis of value. Although the commercial properties comprise a large portion of wealth of the country, less attention was paid to commercial property compared with residential real estate. Commercial property can be divided into two main sectors, offices and shops. 
The Hedonic Regression analysis has been widely used to analyse residential property markets. Dunse and Jones (1995) stated that 'this technique is commonly used in valuation of residential property in the USA, in particular in mass appraisals and it has been used in the UK to a limited extent. Within commercial property sector, it has had only limited application and these are confined to US studies'.

As residential properties, commercial office properties are also heterogeneous goods which comprise a large portion of country's wealth. This is true even in the context of Sri Lanka where the demand for office space has been increased as a result of the growth of the service sector, which indicated its share in Gross Development Product (GDP) was accounted for $52.8 \%$ in the year 2001 and reached up to $59.5 \%$ in 2010. However, less attention was given to the office property market in the country.

In spite of concentration of offices within the Colombo city, capital of the country, experienced in the past, they are now moving from the Colombo city towards suburban areas closer to the city located in Colombo Metropolitan region. This is due to the Government decision to develop Sri Jayewardenepura Kotte as administrative centre of the country which is now speedily implemented and all government institutions located in the Colombo city are being shifted from there to Sri Jayewardenepura Kotte and the administrative unit of Battaramulla in Kaduwela Pradeshiya Sabha. Hence, sub urban areas within the metropolitan region are concentrated with office activities.

In Sri Lanka the demand for office space has been experienced rapid growth during the last decades. One of the main reasons for this is developing trend in the service sector. This has been evidenced by the statistics provided in the Central Bank Reports in which noted that three main contributors for the GDP of the country are the agriculture, industry and service sectors out of which the service sector dominated having a share of more than $50 \%$ of the GDP and has also been gradually increased during the last decade. The main sub sectors in the service sector are whole sale \& retail trade, transport \& communication, banking, insurance $\&$ real estate, government service and private services etc. It is reported that the majority of the service sector activities are taken place in an office environment. Ariyawansa and Dilhani (2010) stated that office market related studies in the country seem not prominent. Also noted that reasons for which may be higher complexities in identifying an exact office market in the country, even though, in most of the other countries have well 
demarcated office markets such as New York, Manhattan office market, Berlin office market \& Hong Kong office market etc.

There are no published research papers which examined determinants of rental values in the office market of the country, and application of hedonic approach was also limited for environmental studies and some residential property market analysis. Considering the need for a research on the office market in the country, this study is aimed at analyzing office market by examining significant determinants of rental values of office properties located in several suburban areas in the administrative capital of Sri Jayewardenepura Kotte. As explained, the Government has made a decision to develop Sri Jayewardenepura Kotte as the administrative capital with the intention of redeveloping the city of Colombo; capital of the country and as well the largest commercial city, by expanding its commercial activities throughout the city. Hence, all the administrative institutions concentrated in the city of Colombo are being shifted from there to Sri Jayewardenepura Kotte.

\subsection{Research Problem}

In the context of Sri Lanka, the highest contributor for the GDP of the country is the service sector having share of $59.5 \%$ of GDP and its annual growth rate was recorded as $17.2 \%$ in the year $2010 / 11$ compared to $12.6 \%$ growth in 2002 . The sub sectors represent the service sector is concerned, it is revealed that the whole sale and retail trade account for highest share of GDP which is $23.6 \%$ in year 2010/11. Moreover, Transportation and Communication, Banking, insurance and real estate etc, and Government services are other predominant sub sectors having share $14.3 \%, 8.8 \%$ and $7.1 \%$ of GDP respectively. Labour force indicators for year 2010 also proved the important contribution of service sector to country having highest percentage of labour force involved in the sector which amounting to $43.1 \%$. Hence, office properties become one of the important aspects of the property market as well as of the economy of the country where all most service sector activities are taken place.

There is lack of econometric studies on the economics of the office property market in Sri Lanka mainly due to general absence of data on rental values. Besides, lack of studies on office rent determinants hide the progress of office rent market. Arbitrary 
decisions of landlords on fixing of office rent may further affect negatively to rental market.

Consequently, studies on office markets are very crucial to policy making agencies to have an overview on the office property market as well as for the valuation practitioners to identify and quantify the factors which affect the value of office properties. The method followed by the traditional valuers is subject to criticism which is based on their personal judgment. Therefore, another approach is needed for valuation practice to minimize the influence of personal judgment at the same time to enable to accelerate the market transaction.

Although the Hedonic Price Model is widely used by developed countries to overcome difficulties arised in identifying and quantifying the property attributes on rental values, in Sri Lanka there is no evidence of use this technique in the field of property valuation. Hence this study attempts to "Analyse the determinants of office rental values through Hedonic Price Model"

\subsection{Significance of the Study}

A valuer is called upon to make a valuation of an interest in a certain property where the value is the amount of capital required to purchase the interest of that property. In many instances properties are occupied by the owner or external person, therefore, the value of such property is dependant on the amount of rent which an occupier is willing to pay for the right to occupy and level of return which an investor would require on his capital.

Since, there are many characteristics associated with properties, difficulties arise in quantifying the influence of these characteristics on rental value of a property. As valuation is based on professional judgment, it is subjective opinion of value. Rent is determined by making relevant adjustments to rental values obtained from comparables which is done subjectively by a valuer depending on his knowledge of the property market.

Consequently, this study which identifies and quantifies the rent determinants on office properties recognizes the importance of study on local office markets and also it would be useful for the valuers to make aware of influence of significant attributes associated 